\title{
Alfabetização: concepções e contextos de ensino
}

\section{Literacy: education's conceptions and contexts}

\author{
Alphabétisation: conceptions et contextes \\ d'enseignement
}

\author{
Ângela Helena Bona JOSEFI
}

\begin{abstract}
RESUMO
O presente trabalho, decorrente do desenvolvimento de atividades desenvolvidas no âmbito do projeto de extensãa "Formação continuada de professores alfabetizadores: uma abordagem para a prevenção das dificuldades de aprendizagem", discute questões relacionadas aos assuntos freqüentemente abordados pela mídia, com suposições acerca das causas do, assim chamado, fracasso no ensino da leitura e da escrita em escolas brasileiras, que acusam o construtivismo como o vilão desse cenário, e apontam o retorno a práticas tradicionais como forma de superação do problema. O estudo realizou-se no contexto de discussões pedagógicas com professores alfabetizadores de 24 escolas municipais de Guarapuava, participantes do projeto, e pautou-se pela busea de esclarecimentos sobre os reais motivos das dificuldades apresentadas por alunos da Educação Básica, no que se refere à leitura e à produção de textos, com o intuito de promover a melhoria do processo de ensino-aprendizagem e a conseqüente superação de dificuldades de aprendizagem. A investigação valeu-se de entrevistas individuais, e discussões em mini-cursos e reuniões com os professores, além de análise de textos dos alunos, e revelou que o problema está ligado a práticas alfabetizadoras inadequadas, decorrentes de um entendimento equivocado das propostas construtivistas.
\end{abstract} interação.

Palavras-chave: alfabetização, ensino-aprendizagem da escrita, ABSTRACT:
The present article, made by the activities' development in a
extension project to prepare literacy' $\mathrm{s}$ teachers: a boarding for the 
prevention of the learning difficulties", argues about questions frequently speak in media concerning the reading and writing failure's causes among Brazilian students. Constructivist is considered as scene's villain and, for this, a lot of teacher defend traditional practices as a way for overcoming the problem. The study was made with literacy teachers in 24 public's schools of Guararema city and investigated the real reasons for students to read and write well in basic education. We have as intention to promote the improvement of the teach-learning process and the consequent overcoming of learning difficulties. The inquiry was used individual interviews, some discussions inside little courses and also some meetings with the teachers, beyond analysis students' texts and solved literacy inadequate practices, we can see some difficulties to understand Constructivist conception.

Index terms: literacy, teaching-learning of the writing, interaction.

\section{RESUME}

Le présent travail, lié au développement d'activités développées dans le contexte d'un projet d'extension « Formation continue d'enseignants en alphabétisation: un abordage pour la prévention des difficultés d'apprentissage » qui a discuté des questions rapportées aux sujets fréquentement abordés par la mídia, avec des hypothèses concernant les causes de, ainsi appelés, échecs dans l'enseignement de la lecture et de l'écriture dans les écoles brésiliennes, nous avons remarqués que les enseignantes accusent la construtivisme comme l'obstacle pour l'apprentissage des élèves et indiquent le retour à des pratiques traditionnelles comme forme de surpassement du problème. L'étude est réalisé dans le contexte de discussions pédagogiques avec des enseignants de la langue portugaise dans de 24 écoles municipales de Guarapuava, après plusieurs moments de recherche et de clarifications sur les réelles raisons des difficultés présentées par des élèves de l'éducation basique, en ce qui concerne la lecture et à la production de textes, avec l'intention de promouvoir l'amélioration du processus de l'apprentissage et le conséquent surpassement de ses difficultés. La recherche s'est value d'entrevues individuelles, de discussions dans des mini-cours et de réunions avec les enseignants avec le but d'analyser des textes des élèves. Les enseignants ont dit que le problème d'apprentissage de la lecture et de l'écriture concerne des pratiques des alphabétisation inadéquates, liées à une concéption melée propositions des construtivistes.

Mots clés: alphabétisation, apprentissage de l'écriture, interaction. 


\section{Breves considerações sobre a alfabetização como processo de letramento}

Há muito se discute sobre a alfabetização como um processo que vai além da simples habilidade de decodificação e codificação da escrita, mas quando as estatísticas educacionais apontam para resultados insatisfatórios do ensino, mostrando que grande parte da população de estudantes apresenta sérios problemas no que se refere à leitura e à escrita, tende-se a atribuir às inovações educacionais, às novas concepções e propostas de alfabetização, fundamentadas em teorias construtivistas sobre o conhecimento, a responsabilidade por tal situação, e, em alguns casos, chega-se a propor o retorno às práticas pedagógicas tradicionais como forma de solução. Em face desse cenário, as questões que nos propusemos discutir com professores alfabetizadores, no âmbito do projeto de extensão "Formação continuada de professores alfabetizadores: uma abordagem para a prevenção das dificuldades de aprendizagem", foram assim definidas: As práticas alfabetizadoras baseadas em concepções construtivistas de ensinoaprendizagem são causadoras do dito fracasso dos estudantes, no que se refere à capacidade de ler e escrever? O retorno às práticas propostas nas velhas cartilhas de alfabetização seria o caminho para superar o problema? Como deve ser o ensino, para que todos os alunos, efetivamente, aprendam a ler e escrever? O estudo sobre essas questões ocorreu durante o período de um ano, em que foram desenvolvidas diversas atividades com os professores envolvidos, e será relatado mais adiante, já que o que nos importa aqui, é que nos dediquemos às considerações a que nos propusemos neste item, no intuito de embasar as discussões posteriores.

Diversos estudos mostram que durante muito tempo o ensino da leitura e da escrita foi entendido como transmissão do saber, como treino mecânico de habilidades ou como mera facilitação. Esse entendimento 
fundamenta-se, respectivamente, nas concepções tradicional, estruturalista e inatista de linguagem e de ensino-aprendizagem, sendo que a alfabetização, nesse sentido, é vista como mera aquisição do código escrito. Nessa percepção, "(....) a leitura e a escrita são tratadas como a mera aquisição da técnica de ler e escrever, com ênfase no componente grafofônico da língua, com um fim em si mesmas, circunscritas às quatro paredes da sala de aula" (BRAGGIO, 1992, p.11). Como conseqüência disso, por um lado, as crianças aprendem a "ler" os textos das cartilhas ou dos livros de alfabetização na escola, mas, por outro, não conseguem operacionalizar a leitura em sua vida cotidiana, e apresentam sérias dificuldades para compreender os textos que circulam socialmente, porque aquilo que aprendem e a forma como aprendem não tem ligação com as práticas sociais de leitura e escrita, dada a ausência de significado das atividades escolares.

Estudos nas áreas da Lingüística e da Pedagogia, não recentemente, apontaram para a necessidade de uma nova concepção de alfabetização, que abrangesse as questões do cotidiano e que ultrapassasse os limites da estruturação. A partir disso, emergiram estudos sobre o letramento, entendido como a condição que assume o indivíduo que se utiliza da leitura e da escrita para posicionar-se e para agir no seu contexto social. Dessa forma, a alfabetização não pode mais restringir-se ao exercício de aprender a codificar e decodificar a escrita, já que é preciso compreendê-la no seu processo histórico e no seu contexto de funcionamento. Se o indivíduo alfabetizado ou não - está inserido em uma comunidade que adota um sistema de escrita, é possível afirmar que o termo "letramento" não se aplica apenas às pessoas alfabetizadas, uma vez que, mesmo os não alfabetizados, convivem na sociedade letrada e, do seu modo, conseguem "ler" a sua realidade e tomar decisões no seu dia-a-dia. Isto permite dizer que não 
existe sujeito iletrado ${ }^{1}$. É claro, entretanto, que o domínio da leitura e da escrita torna o sujeito mais forte, no que diz respeito ao exercício pleno da sua cidadania, uma vez que lhe possibilita o acesso a bens culturais por elas veiculados. Vale dizer, então, que alfabetizar sob a perspectiva do letramento, requer a expansão dos usos da escrita para além dos muros da escola. A escrita, na escola, é construída numa relação tutorial, ou seja, o adulto letrado é quem domina o código, sendo ele que orienta, dirige o processo. Mas isto não significa dizer que as crianças que estão aprendendo não possuam nenhum conhecimento sobre o que seja ler e escrever. Numa atitude crítica, estudar sobre o processo de letramento inclui investigar sobre como interage com a escrita quem é alfabetizado e quem não é alfabetizado, e vive numa sociedade letrada.

\section{A alfabetização na concepção interacionista de linguagem ou sob a perspectiva do letramento}

Sabe-se, como já mencionado, que o processo de construção da língua escrita, pela sua complexidade, exige muito mais do que algumas técnicas e/ou treinos mecânicos, e que a capacidade de ler e escrever depende da compreensão de como funciona a estrutura da língua e do modo como ela é usada no meio social. Dentre outras, as teorias construtivista e histórico-cultural (também conhecida, no Brasil, como sócio-interacionista), elaboradas, respectivamente, por Piaget (1987) e Vygotsky (1988), iluminam a reflexão sobre o processo de alfabetização, na perspectiva a que estamos nos referindo. Não desconhecemos as diferenças nas posturas teóricas de ambos os teóricos e dos seus respectivos contextos sóciohistóricos em que produziram suas teorias. Pretendemos indicar os pontos de concordância mais gerais dessas duas teorias que contribuem para a compreensão do processo de aprendizagem, neste caso, da escrita e da

\footnotetext{
${ }^{1}$ Iletramento entendido como ausência de leitura e escrita no âmbito individual.
} 
leitura.

Para Piaget (1987), a criança é vista como sujeito ativo no processo de aprendizagem, que interage com os outros e com os objetos de conhecimento, num processo permanente de estruturação/reestruturação de esquemas mentais.

Para Vygotsky (1988), o homem constitui-se na sua relação com os outros, o que implica entender que ele (o homem) não possui nada pronto. Nesse sentido, o conhecimento se dá pelas relações entre o indivíduo e o mundo exterior e desenvolve-se num processo histórico, sendo que a aprendizagem ocorre por uma mediação social, em que a linguagem assume papel predominante.

Segundo Benveniste (1982), pela linguagem, ocorre a ação de um indivíduo sobre o outro, o que promove a interação. Daí, a importância da fala nesse processo. Na visão interacionista, a aquisição da linguagem resulta da interação entre o programa mental inato do aprendiz e a linguagem produzida por ele em conjunto com um interlocutor que possui o domínio da língua. Nesse processo, a criança vai testando suas "iniciativas verbais" através do seu relacionamento com os outros. Podemos dizer, então, que as crianças elaboram hipóteses a respeito da linguagem e, na medida do seu uso, vão conferindo as representações que vão "dando certo" e construindo a própria competência interlocutiva.

No caso da educação formal, é fundamental a ação intencional do professor, planejada para interferir nesse processo com a finalidade de levar o aluno a aprender usar adequadamente a linguagem nas suas diversas modalidades. 
A opção por um ensino baseado na gramática tradicional, por exemplo, só daria conta da primeira dessas dimensões e não serviria para levar o aluno à competência no uso da língua. Ora, o uso da língua começa muito antes da vida escolar, e vale considerar que a maneira como a criança capta a linguagem, no seu convívio, influencia fortemente a aprendizagem.

Nesse entendimento, afirma Richter (2000), a linguagem se desdobra em três dimensões indissociáveis: forma, função e estratégia. A opção por um ensino baseado na gramática tradicional, por exemplo, só daria conta da primeira dessas dimensões e não serviria para levar o aluno à competência no uso da língua. Ora, o uso da língua começa muito antes da vida escolar, e vale considerar que a maneira como a criança capta a linguagem, no seu convívio, influencia fortemente a aprendizagem.

\section{O papel ativo da criança no processo de aprendizagem}

Ferreiro e Teberosky (1999), baseadas na teoria construtivista de Piaget, descrevem e classificam as sucessivas etapas de construção da escrita, buscando compreender como esse processo de aprendizagem se desenvolve. Segundo as autoras, a maioria das crianças passa por quatro momentos básicos, independentemente do desenvolvimento da escolarização. Em outras palavras, isso ocorre dependendo das condições que a criança tenha para testar as suas hipóteses e reelaborá-las, e não do nível, série ou ciclo em que se encontra na escola.

É a respeito dessa concepção que nos referíamos anteriormente quando falávamos sobre leituras equivocadas das teorias construtivistas. Muitos acreditavam que a alfabetização deveria seguir passos rígidos ligados a um suposto desenvolvimento linear definido em estágios que indicariam uma organização da aprendizagem baseada numa sucessão de dificuldades crescentes, de forma desvinculada da vida cotidiana da criança. 
$\mathrm{Ou}$, num outro extremo, alguns entendiam, baseados numa concepção inatista de aprendizagem, que a criança, em contato com materiais de leitura e escrita, poderia ficar "à espera" da descoberta natural do seu funcionamento.

Do nosso ponto de vista, hoje, entendemos que o aprendizado da leitura e da escrita é um processo que ocorre num contexto de mediação social em que, no ensino sistematizado, o papel do professor que interage com o aluno, é fundamental.

Aproveitamo-nos da contribuição de Colello (1995) para reler os estudos das duas pesquisadoras que explicam as fases pelas quais as crianças passam e elaboram hipóteses sobre a escrita. Tais estudos demonstraram que, inicialmente, ocorre a escrita pré-silábica, quando a criança ainda não compreende o caráter fonético do sistema, mas já percebeu o caráter arbitrário do traçado gráfico, ou seja, que a representação gráfica não tem compromisso de fidelidade figurativa e que existe a possibilidade de representar um objeto através de um recurso não icônico. Assim, a escrita seria, para ela, outro jeito de "desenhar" as coisas. Nessa fase, a criança inventa "letras" para escrever, enquanto não conhece as letras convencionais. Os sinais criados por ela não têm relação com o valor sonoro do que pretende representar. Posteriormente, há tentativas de escrita com letras convencionais, porém, ainda sem valor sonoro convencional. Pode ocorrer, nesta fase, uma tentativa de relação proporcional entre o traçado gráfico e o tamanho do objeto que pretende representar, sendo, isto, um possível indício da relação de significado que a criança tenta estabelecer entre a sua escrita e o objeto representado. Embora a obra que estamos relendo, tenha sido fundamentada na teoria de Piaget, pensamos ser interessante apontar, aqui, que segundo Vygotsky (1988, p. 130)- ao abordar o simbolismo da escrita e o como as crianças descobrem o princípio da 
mesma- afirma que elas vão avançando para "uma escrita que contém rudimentos da representação" e que "os sinais escritos constituem simbolismos de primeira ordem, denotando diretamente objetos ou ações".

Na escrita silábica, segundo as pesquisadoras piagetianas, percebese considerável avanço com relação à hipótese formulada anteriormente: a criança compreende a escrita como representação da fala ou, em outras palavras, como diria Vygotsky (1988, p. 131), a criança descobre que "se pode desenhar, além de coisas, também a fala". Então, na perspectiva psicogenética, tenta corresponder "partes da fala" com "partes da escrita", fazendo valer uma letra para cada sílaba. Nesse caso, também pode ocorrer o uso de letras convencionais ou inventadas por ela, com ou sem valor sonoro convencional.

Se analisarmos a escrita silábica na perspectiva de Vygotsky, diremos que nesse momento a escrita assume caráter de simbolismo de segunda ordem, porque "compreende a criação de sinais escritos representativos dos símbolos falados das palavras" (1988, p. 130).

\section{A escrita silábico-alfabética (Cf. FERREIRO e TEBEROSKY,} 1999) mostra um momento de transição em que a criança percebe a ineficácia do sistema silábico e tenta acrescentar letras, utilizando-se ora do critério silábico, ora do alfabético, produzindo uma escrita aparentemente caótica.

Para as mesmas pesquisadoras, o passo seguinte dado pela criança é o da conquista da escrita alfabética, em que ela compreende o valor sonoro de cada letra, embora não domine, ainda, as regras e particularidades do sistema da escrita. Aí está o sentido da interferência necessária do professor, para "corrigir" a escrita da criança, a partir da sua tentativa, ou melhor, da sua lógica, de forma que ela, por compreender o seu "erro", avance cada vez 
mais, até que chegue à forma convencionada.

Do nosso ponto de vista, se, de um lado, Piaget defende que a criança, como sujeito ativo, age sobre o objeto de conhecimento, e, de outro, Vygotsky diz que a escrita deve ser sentida como necessária para as crianças que a estão aprendendo, não há como conceber a alfabetização como simples treino das unidades mínimas da escrita para, passo a passo, chegarse ao domínio do código. Nem se pode esperar que a criança aprenda sem uma ação efetiva de ensino. Não há dúvida de que se trata de um processo muito mais amplo e complexo, e de que as diferentes abordagens teóricas a seu respeito podem (e devem) ser vistas como fontes inspiradoras e enriquecedoras de estudos e reflexões que, num processo dialógico, contribuam para a constante melhoria do trabalho pedagógico no ensino da leitura e da escrita.

\section{Por que os alunos (não) aprendem a escrever?}

A partir de reflexões apontadas ao longo deste artigo, buscamos analisar o não-aprendizado da leitura e da escrita- que tem se mostrado polêmico- com o objetivo de contribuir para reflexões ligadas ao desafio de ensinar a ler e escrever de maneira que se promova, efetivamente, a competência dos sujeitos leitores e escritores.

O estudo desenvolvido na cidade de Guarapuava ocorreu por meio de uma investigação de abordagem qualitativo-interpretativa ${ }^{2}$, valendo-se de entrevistas individuais, reuniões com professores e análise de textos dos alunos. Passou-se, essencialmente, no âmbito do desenvolvimento do projeto de extensão em que foram possíveis discussões, troca de

${ }^{2}$ Para Minayo (1996) a pesquisa qualitativa não se preocupa em quantificar, mas em compreender e explicar a dinâmica das relações, trabalhando com a vivência e a compreensão da ação humana. 
experiências e análise de práticas pedagógicas, por parte de um grupo de 52 professores, de 24 escolas da rede municipal de ensino.

O nossos olhar atento de pesquisadora percebeu que- em classes de alunos das séries iniciais do Ensino Fundamental cujo(a) professor(a) compreende e assume, efetivamente, uma postura pedagógica de concepção interacionista, e tem clareza das implicações práticas dessa concepção no dia-a-dia da sua atuação em sala de aula- os alunos desenvolvem, de fato, a competência para ler e escrever, inclusive no que se refere ao domínio da ortografia.

Por outro lado, observou-se que alunos oriundos de classes em que imperaram as práticas pedagógicas de cunho tradicional ou estruturalista e, portanto, condicionadoras, podem até dominar normas ortográficas e gramaticais, mas apresentam-se, na maioria, como meros codificadores e decodificadores, com importantes dificuldades na produção textual e na leitura, em sentido amplo.

Se "ler e escrever são atos lingüísticos (...), a compreensão da natureza da escrita, de suas funções e usos, é indispensável ao processo de alfabetização" (CAGLIARI, 1999, p. 8). O autor considera ingênua a postura de quem ensina o abecedário, as famílias silábicas e a associação de letras para a composição de palavras e frases, como se apenas isto garantisse a aprendizagem da leitura e da escrita. Esse pressuposto orientou-nos em grande parte do desenvolvimento do trabalho cujos resultados ora apresentamos.

As análises e discussões demonstraram, por exemplo, que alguns alunos da $3^{\mathrm{a}}$ e da $4^{\mathrm{a}}$ séries do Ensino Fundamental, apresentavam-se como capazes de ler e escrever apenas pequenas frases, e, em suas tentativas de escrita de textos maiores, evidenciavam um universo pobre de recursos 
lingüísticos, diferentemente de quando se encontravam em conversas descontraídas, em brincadeiras ou relatando fatos ocorridos no seu bairro. As informações davam conta de que esses alunos, invariavelmente, vinham de escolas em que o ensino do alfabeto e das famílias silábicas, de forma descontextualizada, imperava absoluto como ponto de partida para a aprendizagem da escrita, aliado à artificialização da fala para treino da escrita alfabética e ortográfica. Por outro lado, na escrita produzida por alunos vindos de classes das séries anteriores em que o ponto de partida para aprender a escrever era o texto, caracterizado nas suas mais diversas possibilidades enquanto unidade significativa, em atividades que iam da oralidade às tentativas de escrita e leitura, percebia-se certa desenvoltura para escrever, muito parecida com a que utilizavam nas suas argumentações e/ou relatos orais. Chamou-nos a atenção, o fato de que entre estes últimos, havia alguns com bom domínio da escrita ortográfica e das normas gramaticais além da capacidade argumentativa, e, entretanto, outros com boa argumentação e capacidade de ampliação das idéias, porém com dificuldades no que se refere ao domínio ortográfico e gramatical. Os próprios professores envolvidos, ao discutirem essa questão (ressalte-se que participavam do projeto, professores de todas as séries, desde a $1^{\mathrm{a}}$ até a $4^{\mathrm{a}}$, sendo que vários deles, em algum momento atuaram com esses alunos), chegaram à conclusão de que no caso dos que dominavam melhor os aspectos ortográficos e gramaticais dos seus textos, a maioria pertencera a classes em que a correção significativa e participada, aliada ao estímulo à ampliação das idéias para escrever, era promovida sistematicamente pelo professor no processo de produção escrita, desde as primeiras tentativas. Já no caso dos que apresentavam dificuldades, os próprios professores que trabalharam com eles em séries anteriores, admitiram que haviam priorizado o estímulo à criatividade e à argumentação, dando menor importância aos processos de correção gramatical e ortográfica, entendendo que haveria 
futuramente um momento mais adequado para trabalhar questões dessa natureza.

Isto nos levou a colocarmo-nos diante de outra questão: o quê, como e quando ensinar, para formar leitores e escritores competentes? Buscamos, então, em autores como Geraldi (1993), Soares (1998), Ferreiro (1987) e Colello (2003), além do próprio Cagliari (1991, 1999), a luz para a necessária reflexão a esse respeito. Os estudos mostraram que diante do desafio de ensinar a ler e escrever há que se considerar duas percepções da língua, que devem ser conciliadas em um único processo: "por um lado, um sistema estruturado de tal forma que não permite transgressões, sob pena de perder a dupla condição de inteligibilidade e comunicação, e, por outro, um conjunto de recursos suficientemente aberto que permite dizer tudo, sendo, portanto, permanentemente disponível ao poder de criação do sujeito" (GERALDI, 1993). Assim, a sistematização desse ensino implica que seja atribuída igual importância aos aspectos ligados à criação e à argumentação, e aos aspectos ligados à normatização da língua. Não há, então, possibilidade de dissociação entre o processo de ensinar/aprender a escrever e o processo de usar a escrita.

Soares (1998) defende a complementaridade e o equilíbrio entre um e outro. Em outras palavras, "a escrita é importante na escola, porque é importante fora dela, e não o contrário" (FERREIRO, 1987, p. 11).

\section{Considerações finais}

O resultado das discussões ocorridas no percurso do trabalho realizado foi a compreensão de que o problema do ensino da língua escrita não está nas propostas que se baseiam em concepções construtivistas ou interacionistas de ensino-aprendizagem, mas em práticas que decorrem do entendimento equivocado dessas propostas, e que, em consequiência, se 
dizem construtivistas mas não o são de fato. Portanto, o retorno a práticas que se reduzem ao simples exercício da consciência fonológica pela associação de sons e letras para produzir corretamente palavras ou frases seria um grave retrocesso.

Não significa que o trabalho com as unidades mínimas da escrita não seja necessário. Significa que ele deve ocorrer como exercício significativo de análise lingüística em contextos de uso e funcionamento da língua escrita. Assim sendo, aproveitamo-nos, novamente, de Colello (2003), para dizer que o ensino deve ser enfrentado a partir da necessidade de compreender o aluno em seu processo cognitivo de elaboração absolutamente pessoal - porém não sem a ação intencional de quem ensina - que ocorre em um contexto que não só fornece informações específicas, mas também motiva, dá sentido e concretude ao que se deve aprender. Então, mais importante do que definir-se por uma determinada metodologia ou por uma determinada teoria, é compreender como cada aluno aprende, para, então, atuar no seu processo de construção do conhecimento, numa perspectiva, efetivamente, interativa. Pode-se dizer que é possível, assim, alfabetizar letrando, ou seja, ensinar a ler e escrever através de atividades efetivamente contextualizadas.

Ao final das atividades previstas, em discussão avaliativa dos trabalhos, os professores deram depoimentos relativos a conquistas dos seus alunos, percebendo que vários dos seus alunos que se encontravam em risco de reprovação, superaram determinadas dificuldades, a partir de interferências ou atividades sugeridas durante os mini- SOARES, Magda (1998). Letramento: um tema em três gêneros. Belo Horizonte: Autêntica cursos ou nas reuniões.

$\mathrm{O}$ exposto neste artigo pretendeu demonstrar que processos de formação continuada de professores são imprescindíveis como instrumento 
de contribuição para a constante reflexão e conseqüente melhoria da qualidade do trabalho pedagógico nas escolas.

\section{REFERÊNCIAS:}

BENVENISTE, Émile (1982). A natureza dos pronomes. In: DASCAL, M. (Org.). Fundamentos metodológicos da lingüística. Pragmática. Campinas: Editora do Autor.

BRAGGIO, Silvia L B. (1992). Leitura e alfabetização: da concepção mecanicista à sociopsicolingüística. Porto Alegre: Artes Médicas.

CAGLIARI, Luis C. (1991). Alfabetização \& lingüística. São Paulo: Scipione.

Paulo: Scipione.

(1999). Alfabetizando sem o bá-bé-bi-bó-bu. São

COLELlO, Sílvia M. G. (1995). Alfabetização em questão. Rio de Janeiro: Paz e Terra.

(2003). A pedagogia da exclusão no ensino da língua escrita. Revista VIDETUR, ${ }^{\circ} 23$ Porto/Portugal, Mandruvá, p. 2734. Disponível em: 〈http://www.hottopos.com>. Acesso em: 18 mar. 2008.

FERREIRO, Emília; TEBEROSKY, Ana (1999). Psicogênese da língua escrita. Porto Alegre: Artes Médicas.

FERREIRO, Emília. Alternativas para a compreensão do analfabetismo na região. In: SEMINARIO REGIONAL SOBRE ALTERNATIVAS DE ALFABETIZAÇAO PARA A AMÉRICA LATINA E O CARIBE. Brasília: Ministério da Educação/OREALC.

GERALDI, João Wanderlei (1993). Portos de passagem. São Paulo: Marins Fontes.

MINAYO, M. C. S. (1996). O desafio do conhecimento: pesquisa qualitativa em saúde. São Paulo: Hucitec.

PIAGET, Jean (1987). O nascimento da inteligência na criança. Rio de Janeiro: Guanabara. 
RICHTER, Marcos Gustavo (2000). Ensino do português e interatividade. Santa Maria: Ed. Da UFSM.

SOARES, Magda (1998). Letramento: um tema em três gêneros. Belo Horizonte: Autêntica.

VYGOTSKY, L. S. (1988). A formação social da mente. São Paulo: Martins Fontes.

\section{Autora:}

Ângela Helena Bona Josefi

Universidade Estadual do Centro-Oeste, UNICENTRO - PR.

Contato: angelabona@ig.com.br

\section{Como citar este artigo:}

JOSEFI, Ângela Helena Bona. Alfabetização: concepções e contextos de ensino. Revista ACOALFAplp: Acolhendo a Alfabetização nos Países de Língua portuguesa, São Paulo, ano 5, n. 9, 2010/ 2011. Disponível em: <http://www.acoalfaplp.net>. Publicado em: setembro de 2010 - março de 2011.

Recebido em outubro de 2009./ Aprovado em dezembro de 2009. 